\title{
Research on the Construction of Energy Internet Ecosystem in State-owned Enterprises
}

\author{
Wang $\operatorname{Han}^{1 *}$, Meng Weixuan ${ }^{1}, \mathrm{Xu}$ Yunfei $^{1}$ \\ ${ }^{1}$ State Grid Energy Research Institute Co., Ltd., Beijing, 102209, China
}

\begin{abstract}
This paper systematically sorts out the relevant theories of the ecological circle, summarizes the theoretical understanding levels of the ecological circle, and proposes the theoretical understanding and connotation definition of the ecological circle. And through in-depth analysis of the development practices of advanced ecological enterprises, the basic logic and key elements of ecosystem construction are summarized, and a practical ecosystem construction methodology that helps guide the exploration of ecological value and promote business innovation is formed.
\end{abstract}

\section{Introduction}

Establishing an ecological circle and implementing an ecological strategy can help enterprises achieve creative reorganization and utilization of cross-industry elements, thereby breaking the path dependence of enterprise development, and can create more value for users and then for the enterprise. In recent years, the implementation of ecological development has been the unanimous choice of many Internet companies, and has been proven to be an important strategic means to adapt to a rapidly changing environment, effectively grasp strategic opportunities, and better serve target customers, and to support business development and build core competition in the enterprise.

First, leading the construction of the ecological circle can share resources, cooperate and innovate with various types of partners in the upstream and downstream of the industrial chain, and achieve mutual benefit and win-win results.

Second, state-owned enterprises need to break the traditional path dependence and change from "doing their own" to "doing it together", integrating the strengths of various cooperative entities with the construction of an ecological circle, promoting the reorganization of different elements of the main body, integration and innovation, and jointly achieving the strategic goals. [1]

Third, through the construction of ecosystems at all business levels, the ecological network will be continuously expanded to promote the development of the company's corporate ecosystem, which will provide a richer resource network, experience advantages, and cooperation foundation for various types of business innovation and development, which will help various business innovations to emerge.

\section{Summary of basic theory of the ecosystem}

\subsection{Development background}

With the rapid development of the Internet economy and the sharing economy, traditional competition methods are shifting from the original competition among individuals, competition between supply chains and value chains to competition among business ecosystems. In a complex and open environment, companies generally tend to build interdependent, interdependent, and symbiotic business ecosystems with many entities to cultivate new competitive advantages.

New customer demands are driving change in value creation. The widespread application of Internet technologies has made networked, customized, decentralized, and de-intermediate a universal trend. User requirements have gradually shifted from the pursuit of a single, universal product function to a more emphasis on personalized, integrated requirements. The interaction between enterprises and users and between different users is more frequent and complicated. [2] Together, they will participate in the innovation, design, production and value creation of products and services, and the original mode of creating user value within the enterprise will be broken. Enterprises use the business ecosystem to provide users with personalized, customized, and timely response products and services, which will become an inevitable choice to meet user needs and create user value.

The new situation of ecological competition requires companies and stakeholders to grow together. Different from the previous direct competition between enterprises and the competition between industrial chains, the current competition is mainly competition between business ecosystems. In the ecological competition stage, the

${ }^{*}$ Corresponding author's e-mail: wanghan@sgeri.sgcc.com.cn 
boundaries of competition will cross different industries. By closely interacting with ecosystem partners, companies can jointly promote the emergence of innovation and achieve value creation. Enterprises are required to grow together with related companies, suppliers, customers, social organizations, the public, and the natural environment, and to adapt to the increasingly open and complex business environment brought about by economic globalization and technological progress.

The digital economy is driving companies to focus on fostering ecological advantages. As the industrial economy transitions to a digital economy, resource elements are highly dispersed and rapidly flowing, and resource allocation is rapidly iterating, making it more difficult for a single enterprise to realize value creation through resource organization and connection. The source of sustainable advantages of enterprises has gradually shifted from the division of labor in the upstream and downstream of the value chain to the symbiosis and collaboration on the value network. Furthermore, companies are required to break through the competitive advantages derived from the optimization of internal value chain activities and the accumulation of resource capabilities, rely on the value chain extension and mutually beneficial coexistence, and implement rexsource pooling and system reconstruction based on the ecosystem to drive value creation and value capture.

\subsection{Function}

The business ecosystem, through cross-industry integration of resources, innovation in value creation, and reduction of transaction costs, promotes core companies to innovate business models, cultivate new profit points, build market competitive advantages, and build a broader voice.

Gain complementary resources and capabilities to promote business model innovation. The ecosystem provides enterprises and partners with a smoother resource interaction and sharing mechanism and plays the role of a "resource pool". This is beneficial for companies to break through the limitations of resource endowments and corporate boundaries, quickly obtain heterogeneous and complementary resources, and efficiently cultivate the ability to integrate superior resources. In addition, it will drive companies to define new value relationships and transaction structures between ecosystem partners in accordance with new customer needs, promote adjustment of their business scope and functional interfaces, and promote business model innovation in the entire ecosystem.

Support the expansion of new businesses and foster new profit growth points. [3] The development of the ecosystem often means lower cost of resource acquisition and more connection points of derived value. The rich advantageous resources of the ecosystem and the deep dependence on reciprocity between companies and many partners facilitate companies to accurately identify new customer needs in a wider range. It also efficiently integrates value chain activities in the ecosystem, allocates scarce resources at low cost, promotes the depth and breadth of business innovation, and further forms new profit growth points through business integration and cultivation.

Build and share core capabilities together to create market competitive advantages. Based on the pursuit of common interests, enterprises and partners absorb and integrate the value elements of the ecosystem, and jointly build and share the core competitiveness of the ecosystem, reducing the burden of production costs brought by the heavy asset management of enterprises, and reducing the transaction costs in the process of acquiring external resources. In addition, it empowers enterprises and partners to more accurately grasp changes in customer needs, adapt to complex and dynamic market environments more quickly, and provide high-quality products and convenient services more efficiently.

Improve social contribution and strengthen the right to speak of industrial development. Based on the concept of win-win cooperation, the company establishes an ecological community of interest. It is conducive to reducing market transaction costs, expanding the scope of sharing of tacit knowledge, core technologies and other resources, enhancing the efficiency of scarce resources, promoting the coordinated development of related industries, and promoting the healthy upgrade of social needs. To further improve social contribution, industrial development influence, and the right to speak.

\subsection{Typical definition}

The ecosphere, as a biological concept, was introduced into the field of commercial research starting with Moore (1993) and has been widely recognized. Moore (1993, 1998) first defined the business ecosystem as an economic complex based on the interaction of organizations and individuals (organisms in the business world). It is a dynamic structure composed of customers, suppliers, major producers, investors, trading partners, standardsetting agencies, labor unions, governments, social and public service organizations and other stakeholders with certain interests.

After Moore, other scholars mainly define the business ecosystem from the two dimensions of network structure and value creation:

Network structure. The research represented by Moore focuses on the different organizational populations and subsystems within the business ecosystem. The "populations" are functionally coordinated and complementary to support the realization of the functions of the ecosystem. First, emphasize the symbiotic relationship between enterprises, that is, close interaction, value and benefit exchange. Secondly, the ecosystem is composed of different "species". For example, consumers, market intermediaries, suppliers and enterprises constitute the main "species", and also include owners, risk bearers and other "species" related to power. [4]

Value creation. Taking Garn-sey \& Leong (2008) as the representative, from the perspective of core enterprises, describe the cooperation network of core enterprises, explain the formal and informal interaction mechanism between enterprises, and propose that the ecosystem is 
leveraging member enterprise resources, preventing competitors, and fostering new ones. Profit points and provide value beyond a single business.

\subsection{Connotative features}

Based on a review of the opinions of experts and scholars at home and abroad and the classic literature, the current theoretical world mainly describes the connotation characteristics of the ecosystem from the dimensions of symbiosis, dynamics, diversity, evolution, and integration.

Symbiosis. Within the ecosystem, member companies exhibit an interdependent relationship, and the interests of each member are linked to other members and the overall healthy development of the business ecosystem.

Dynamic. The business ecosystem consists of suppliers, consumers, producers, sellers, investors, governments, and related institutions. The members of the system form a value chain through the flow of materials, funds, and information. The units at both ends of the value chain are symbiotic relationships. Multiple symbiotic relationships form the value network of the business ecosystem.

Evolutionary. A business ecosystem will inevitably experience the four stages of development, expansion, leadership, renewal, or death, and it has certain periodicity. Changes in internal members or changes in the external environment may affect the development and evolution of a system. Each member is trying to improve himself as much as possible to achieve synchronous development with surrounding members and adapt to the environment.

Integration. It is mainly manifested in the integration of internal activities and external system integration. Cultivate core competitiveness through integration of internal value chain activities. Through the circulation and connection of matter, information and energy in the system's internal value network and the external environment, the collection becomes an organic whole.

\section{Analysis of the Mechanism of Ecosystem Construction and Evolution}

\subsection{Definition of connotation}

\subsubsection{Enterprise ecosystem and business ecosystem}

The ecosystem in business management usually includes the business ecosystem and the enterprise ecosystem. Among them, the business ecosystem is mainly dependent on specific businesses, and a large enterprise can have multiple business ecosystems in different business areas. The corporate ecosystem is continually evolving in the commercial ecosystem, converging and evolving, and exists around a large core enterprise.

Generally, the business ecosystem is a core business with resource aggregation capabilities under specific business scenarios, focusing on clear value creation goals, using a variety of cooperation methods, integrating resources, connecting value points, and leading the construction of an orderly, dynamic value relationship network.

To understand and grasp the business ecosystem, we must see both "nodes" and "network relationships".

"Node" represents the main body. The ecosystem often has a core leading enterprise, and associated customers or suppliers, manufacturers, distributors, and other partner companies or institutions (individuals) on multiple value chains. Trading partners, standard-setting agencies, unions, governments, social services, and other stakeholders.

"Network relationship" represents the interactive relationship between the subjects. It is the main constituent of the ecosystem. Depending on the specific business, it can achieve efficient flow of products (services), funds, and information across multiple value chains through transactions, alliances, equity participation, and opening. Thereby reducing transaction costs, sharing operational risks, sharing scarce resources, and jointly creating the overall competitive advantage of the ecosystem.

\subsubsection{Ecosphere construction connotation}

In the sub-ecological construction stage, it mainly focuses on user needs to integrate multiple heterogeneous elements as the dominant logic, focuses on clear value propositions, identifies shortfalls in value elements, and accurately locates the capabilities and needs of potential ecological members. Factor aggregation and division of labor help eco-owners establish significant market positions.

In the stage of ecological expansion (formation of the corporate ecosystem), resource sharing is used as the basic means to promote the flow of elements in multi-business sharing (such as user resources), in the sharing process or to explore new value propositions, or build new technical capabilities, In order to provide customers with new products or services, promote business development and border expansion, while attracting more ecological members to join and expand the ecological boundary.

\subsection{Analysis of ecosystem construction and evolution mechanism}

In general, the construction of an ecological circle in an enterprise is about the process of ecological construction, ecological utilization, and ecological management. Building, utilizing and managing the ecology is a process of gradual deepening and cyclical evolution. It is not only necessary to open up the upstream and downstream relationships at the business level, establish ecological connections with business partners, and create a businesscentric sub-ecology. [5] At the same time, the enterprise level strengthens the sub-ecological circle's connection with each other, the flow of factors, and the integration of innovation through technology empowerment, capital empowerment, and user resource introduction, which can promote co-evolution within and between sub-ecosystems, and achieve the development and evolution of the corporate ecosystem.

During the construction phase of the business ecosystem, the company focuses on its core business, 
forms a single business model based on the core business, and strives to open up the relationship between the core business and external market players. In the process of integrating into industrial development and business synergy, a sub-ecosystem around core business upstream and downstream is gradually established to expand the business ecological boundary.

In the utilization phase of the business ecosystem, companies have developed two or more business subecologies, and multiple business models have developed together. Companies need to take advantage of their existing business ecosystems and build synergies to bridge the boundaries between the company's different businesses in order to promote business model innovation. At this stage, not only integration and innovation at the business level and business model changes are needed; a comprehensive strategic evaluation at the company level is also required to identify the availability of different business ecosystems and increase the success rate of business model changes and innovation to expand the company Ecological border.

\section{Conclusion}

The energy internet ecosystem includes two levels.

The first level is the business ecosystem based on the energy internet sub-business.

That is, around the overall goal of building an energy internet enterprise, various energy internet sub-businesses are identified, and several business ecosystems are formed around each energy internet sub-business, including various types of ecological members and their interactive relationship networks.

The second level is the company's energy internet enterprise ecosystem.

It is an enterprise level ecosystem, which is formed by the continuous evolution and connection of multiple energy Internet sub business business business ecosystem, and further evolved with the development of business. Under the leadership of the company, with the expansion of its members, the network relationship is more complex and stronger, forming a highly complex, orderly and common development value relationship network.

\section{ACKNOWLEDGMENT}

This work was supported by State Grid Corporation of China Science and Technology Project "Research on the Company's Development Theory and Evaluation System of 'Strengthening, Optimizing and Growing', Under the Background of the Reform of State-owned Assets and State-owned Enterprises".

\section{REFERENCES}

1. Liang, Y., Wang, C. Business Ecosystem Wins Competition 3.0 Era, in: China Telecom, vol.3, Beijing, China, 2019, pp. 57-59. DOI: 10.3969/j.issn.1671-3060.2019.03.016.

2. Zhang, Y. Liu, R. The Formation Path of Platform
Companies' Ecological Advantages in the Business Ecosystem, in: Economics and Management Research, vol.39(09), Beijing, China, 2019, pp. 114124. DOI: $\quad 10.13502 /$ j.cnki.issn $1000-$ 7636.2018.09.010

3. Liu, L. Service-oriented Transformation of Manufacturing Enterprises: a new Model of Internet Transformation, in: Market Modernization, vol.13, Beijing, China, 2018, pp.19. DOI: 10.14013/j.cnki.scxdh.2018.13.011

4. Tan, J. Research on the Construction of Business Ecosystem of Platform E-commerce Enterprises, in: Productivity research, vol.3, Taiyun, China, pp. 139143+156. DOI: $\quad$ 10.19374/j.cnki.141145/f.2019.03.023

5. Yang, Z. Platform Corporate Social Responsibility: Boundary, Governance and Evaluation, in: Economist, vol. 5, Chengdu, China, pp. 79-88. DOI: 10.16158/j.cnki.51-1312/f.2018.05.011 